\title{
A Influência Perene do Processo Civil Romano nas Instituições Processuais Contemporâneas
}

\section{Fernando Antônio Negreiros Lima}

Mestre em Direito (UFG). Professor de Processo Civil (FA7). Procurador da República no Ceará. negreiros@prce.mpf.gov.br

Sumário: Introdução. 1. A evolução do processo civil romano. 2. O processo das ações da lei (legis actiones). 3. O processo formular (per formulas). 4. O processo da cognitio extra ordinem. 5. O processo civil na Europa após a queda de Roma. 6. O processo no direito justinianeu. 7. O processo no direito dos povos germânicos e no direito feudal. 8. O processo canônico. 9. A recepção do direito romano. Conclusão. Referências.

Resumo: A influência do direito romano sobre toda a construção jurídica ocidental é bastante conhecida. Também no campo processual essa influência ainda hoje se manifesta de forma bastante palpável. O presente artigo procura analisar as diversas fases do processo romano e de sua evolução enquanto o império romano dominou o cenário mundial e mesmo ao longo dos séculos que se seguiram à sua queda. Busca-se, ademais, detectar as manifestações mais visíveis dessa influência, através dos institutos processuais que, sob roupagem moderna, ainda revelam os traços latinos. Examinam-se as relações do direito romano recepcionado com as novas culturas bárbaras e com o processo canônico. Em conclusão, demonstra-se a sobrevivência do direito romano e, portanto, da necessidade de seu estudo nos cursos jurídicos.

\section{NTRODUÇÃO}

Nunca é demais sublinhar a importância do direito romano na história da civilização ocidental. É suficiente lembrar que, mesmo muitos séculos depois da queda do grande império, suas leis e instituições continuaram a reger as nações da Europa medieval e até mesmo da era moderna. A doutrina mais autorizada o afirma: 
Três vezes Roma ditou leis ao mundo, três vezes ela serviu de traço de união entre os povos: pela unidade do E stado, inicialmente, quando o povo romano ainda estava na plenitude sua potência; pela unidade da Igreja, em seguida, depois da queda do império romano, e a terceira vez, enfim, pela unidade do direito, com a recepção do direito romano na idade média. A opressão e a força das armas levaram, na primeira vez, a tal resultado; foi a força intelectual que prevaleceu nas outras épocas. (Ihering, 2004, t. I, p. 1-2) (tradução nossa)

A força intelectual da grande obra jurídica romana ainda hoje subsiste, notando-se a renovação da consciência da necessidade de seu estudo nos cursos jurídicos de nossa época, como base imprescindível para a formação dos novos juristas.

No que diz respeito ao processo civil que se estuda e pratica nos dias atuais, a raiz romana da imensa maioria de seus institutos - que não se restringe ao emprego, quase sempre equivocado, ou descontextualizado, de palavras, expressões e brocardos latinos - é facilmente atestada por qualquer investigação mais detida, nada obstante escape, via de regra, à atenção ou ao conhecimento dos profissionais jurídicos.

Um breve repasse da evolução e da história do processo civil romano é, portanto, o objeto do presente estudo.

\section{AEVOLUÇÃO DO PROCESSO CIVIL ROMANO}

Os historiadores costumam dividir a história do processo civil romano em três fases: o período das ações da lei (legis actiones), o período do processo formular (per formulas) e o período da cognição extraordinária (cognitio extraordinaria) (T ucci e Azevedo, 2001a, p. 39-47). Essas fases se sucederam ao longo da existência do Estado romano. As duas primeiras abrangeram, basicamente, mas não de forma exclusiva, os períodos da realeza e da república, constituindo o que se designou ordem dos juízos privados, ou ordo iudiciorum privatorum; a última fase se refere, preponderantemente, à era dos Caesares e ficou conhecida como ordo iudiciorum publicorum, vale dizer, ordem dos juízos públicos.

Deve-se acentuar que também em Roma o ponto inicial dessa evolução é a vingança privada. Ensina, a esse respeito, Ihering que "os primeiros movimentos do sentimento do direito lesado consistem, inevitavelmente, em uma reação violenta contra a injustiça causada, na defesa privada e na vingança.” (2004, t. I, p. 119) (tradução nossa).

Nem poderia ser diferente.

O Estado, em sua infância, não é capaz de enfrentar ainda a força do individualismo - da autoridade patriarcal e religiosa, por exemplo - e se vê forçado, em consequência, a deixar aos próprios interessados a solução de suas controvérsias.

Nesse sentido, atente-se para a lição: 


\begin{abstract}
Na origem, toda necessidade da vida encontra sua satisfação na vida mesma. Antes que um desenvolvimento mais acentuado venha a fazer surgir, pouco a pouco, órgãos especiais para os diversos interesses e as diversas necessidades da comunidade, estes não se achavam largados ao acaso. A defesa privada natural ou a virtude curativa da vida interferiam em seu favor. [....] Que não haja, de forma alguma, juiz ante o qual se possa convocar o culpado, para prestar contas de sua infração, nem por isso este deixará de ser atingido, talvez até de modo mais certo e mais rápido que na mais perfeita e organizada justiça criminal. É a justiça popular que faz respeitar a moral popular ofendida. [....] Quando a pretensão tinha natureza duvidosa, sua persecução pela via da justiça privada devia necessariamente levar a uma luta selvagem, e teve de ser substituída pela criação de instituições destinadas à decisão de tais controvérsias [destaque nosso]. (Ihering, 2004, t. I, p. 119-125)
\end{abstract}

Mas, a partir da constatação, em muitos casos, de que a pretensão manifestada por um dos contendores era francamente duvidosa, talvez injusta mesmo, somente prevalecendo em razão de circunstâncias específicas (maior força física, maior número, debilidade de uma das partes, por exemplo), surge timidamente a atividade estatal, na busca de impor freios ao uso desmedido e aleatório da força (KASER, 1999, p. 429)ํ. Acentua Ihering:

Essa distinção entre o direito ou a injustiça contestável ou incontestável exerce, em toda parte, na origem do desenvolvimento do direito, uma influência reguladora sobre sua formação; à medida que o direito progride, esta distinção perde sua importância. Mas ela está tão profundamente impregnada no direito e no processo antigos de Roma, que é possível designá-la como a idéia fundamental que caracteriza toda a arquitetura do sistema antigo. Não há processo senão onde a pretensão é contestável por natureza. Quando ela é evidente, a execução ocorre imediatamente; é o interessado apenas que a promove, não tendo que intervir as autoridades. Neque enim qui potest in furem statuere necesse habet adversus furem litigare - essas palavras do jurisconsulto romano, que eu tomei como epígrafe do presente capítulo, exprimem a idéia fundamental da ordem jurídica da Roma antiga. Aquele que tem um direito evidente não precisa recorrer à autoridade, seja para fazê-lo reconhecer, seja para realizá-lo. Sua realização diz respeito apenas ao interessado." (2004, t. I, p. 119-125)

Funda-se, portanto, na distinção entre manifesta justiça e injustiça manifesta a passagem da pura e simples vingança privada, ilimitada e sem qualquer controle por parte do Estado, para uma forma conciliatória (que, sem deixar de ser justiça privada, na sua origem e forma de execução, é já, contudo, objeto de censura estatal, para coibirlhe os excessos).

\footnotetext{
1 "Como em todos os povos, a história do processo para efectivar direitos privados começa em Roma com a força privada limitada e controlada pelo Estado."

2 Tradução livre do texto latino transcrito: "Pois não tem necessidade de litigar contra o ladrão aquele que contra o ladrão pode agir."
} 


\title{
20 PROCESSO DAS AÇÕES DA LEI (LEGISACTIONES)
}

O primeiro período por que passou a evolução do processo civil romano foi o das legis actiones. Uma observação importante, a se ter em conta desde logo, diz respeito ao verdadeiro significado da locução ações da lei.

Para o cidadão romano, ter ação era uma expressão de significado aproximadamente idêntico ao que hoje possui a expressão ter direito a alguma coisa (WINDSCHED, 1999, p. 49)³. Em número de cinco, as ações da lei caracterizavam-se pelo formalismo acentuado.

O jurisconsulto Gaius assim explica:

\begin{abstract}
As ações empregadas pelos antigos denominavam-se ações da lei, ou pelo fato de se originarem das leis (pois, na época, não existiam ainda os editos do pretor, que mais tarde introduziram várias ações) ou por se adaptarem às palavras das próprias leis, conservando-se, por isso, imutáveis, como os termos das leis. Daí ter-se respondido que perdia a ação quem, agindo por causa de videiras cortadas, empregava o termo videiras (vites); pois a Lei das XII Tábuas, na qual se fundamentava a ação por videiras cortadas, empregava a expressão árvores cortadas (arboribus succisis) em geral. As ações da lei eram cinco: sacramentum, iudicis postulatio, condictio, manus iniectio e pignoris capio. (2004, p. 182-183)
\end{abstract}

Duas eram as fases em que se desenvolvia o procedimento: inicialmente (fase in iure), ambas as partes tinham de comparecer, por livre e espontânea vontade, diante do praetor - magistrado público; em caso de o réu não estar presente, cabia ao autor realizar a citação (in ius vocatio), inexistindo serventuários públicos que se incumbissem de tal ato (MEIRA, s/d, p. 28); de comum acordo, as partes deviam indicar o iudex cidadão, que atuaria como árbitro - ao qual submetiam a questão; não havendo prévia escolha do árbitro pelas próprias partes, o pretor poderia fazer a indicação daquele a quem competiria o julgamento propriamente dito (fase apud iudicem).

Todo esse procedimento ocorria diante de testemunhas (testes) e, por isso mesmo, o seu ato culminante, que obrigava as partes, impondo-lhes a aceitação do veredito, recebia o nome de litiscontestatio. O árbitro (iudex) decidia soberanamente, caso

\footnotetext{
3 "O que os romanos chamam actio, do ponto de vista da concepção jurídica hodierna, é uma pretensão reconhecida pelo direito." Célebre é a polêmica travada entre esse eminente jurista alemão e seu conterrâneo e opositor, Theodor Mutter. Este, em contestação ao estudo antes referido, sob o extenso título Sulla dottrina dell'actio romana, dell'odierno diritto di azione, della litiscontestatio e della successione singolare nelle obbligazioni (Windsched, 1999, p. 239), opôs-se veementemente a tal entendimento, sustentando que a "ação do lesado é, então, a faculdade de induzir o estado a fazer valer seu direito contra o violador [....] é a pretensão do titular do direito à obtenção de uma fórmula [....]". Em réplica (1999, p. 291) volta a insistir Windscheid: "Quando os romanos dizem que alguém tem uma actio, que alguém faz jus a uma actio, pretendem, com isso, dizer precisamente aquilo que nós pretendemos dizer quando atribuímos a alguém uma pretensão (Anspruch) jurídica." (tradução nossa)
} 
tivesse, após o debate oral da causa e a produção da respectiva prova, chegado a uma conclusão. Se, porém, "não lograsse formar sua convicção a respeito de determinada causa, poderia simplesmente declarar sibi non liquere (não me parece claro), ensejando que as partes retornassem ao magistrado para a escolha de um novo julgador" (TUCCI e AZEVEDO, 2001a, p. 59).

Rigidez do processo, formalismo exagerado, necessidade de repetição solene de palavr as exatas e, até mesmo, de gestos determinados: tais eram as características fundamentais, que marcavam o processo civil de então, fazendo-o arcaico e obsoleto e terminando por torná-lo impraticável.

Arangio-Ruiz aponta pelo menos três graves defeitos, que comprometeram o processo das ações da lei: a) a dificuldade de aprender de cor as declarações solenes a serem feitas ante o magistrado, agravada ainda pelo fato de que, perdida uma ação pelo uso inadequado das palavras, não se podia propô-la novamente (bis de eadem renesit actio); b) o sistema depositava excessiva confiança na prova testemunhal, na boa-fé e na memória dos depoentes; e c) a atribuição de propriedades mágicas, sagradas mesmo, às palavras (admissível, nos primórdios da sociedade romana, quando o elemento religioso se impunha facilmente, mas cada vez mais contestado, no decurso dos anos).

Ademais, tal processo era restrito ao cidadão romano, o que o fazia anacrônico, em um mundo em que Roma, cada vez mais expansionista, econômica e militarmente, alargava suas relações com outros povos.

Por fim, ressalte-se que, mesmo entre os romanos, a maior complexidade e a crescente diversidade dos casos, trazidos ao pretor, pouco a pouco obrigou a que esse magistrado inovasse em relação às ações da lei, restritas apenas às cinco modalidades descritas por Gaius. Não podendo criar ações novas, visto que só a lei podia fazê-lo, o pretor passou, então, a conceder interditos (interdictum, pl. interdicta), isto é, comandos, ordens - a requerimento de um particular e em face de outro - para que se fizesse ou deixasse de fazer alguma coisa (TUCGI e AZEVEDO, 2001a, p. 112-113). Assumiu, assim, um papel cada vez mais relevante, sendo esse um dos mais importantes marcos distintivos da nova fase do processo civil romano, denominada de processo formular.

\section{PROCESSO FORMULAR (PER FORMULAS)}

Em um primeiro contato, a fórmula, do ponto de vista do jurista moderno, é de difícil compreensão, nada havendo de semelhante no processo atual. Sinteticamente, pode-se dizer que se tratava de um breve texto do pretor, dirigido ao iudex, contendo as circunstâncias da causa, as partes e as decisões possíveis, instruindo-o sobre como julgar. Em que pese seu interesse hoje apenas histórico, um exemplo vem a calhar: 
Em razão de Aulus Augerius ter vendido a Numerius Negidius um escravo, tu, juiz, condenarás Numerius Negidius a dar ou a fazer o que quer que este tenha de fazer ou dar, nestes limites, se isso resultar devido. Se não resultar, absolve-o. (ArangioRuiz, 1980, p. 32)

A introdução desse novo sistema de processo guarda estreita relação com o incremento e desenvolvimento das relações comerciais entre romanos e estrangeiros. Como estes últimos não eram cidadãos romanos, era-lhes vedado o acesso ao processo das ações da lei: não podiam recorrer aos magistrados então existentes, nem invocar, em sua condição, as palavras solenes daquele procedimento.

Assim, foi-se impondo, por volta do século III, antes de Cristo, a necessidade da adoção de um novo tipo de processo - mais ágil e avesso aos excessos formais - que contemplasse essas novas relações. Explica-o Arangio-Ruiz, lembrando o fato de que os estrangeiros não gozavam, em Roma, de direitos civis:

\begin{abstract}
Mas as relações comerciais, se desenvolvendo em larga medida após a conquista da Itália e de suas ilhas fizeram necessário, no ano 243, antes de Cristo, a criação de um magistrado especial, que tinha jurisdição sobre as diferenças entre comerciantes de nacionalidade diversa, e que se chamou pretor peregrino, ou estrangeiro, em oposição ao pretor urbano, competente para os litígios entre cidadãos. Como seu colega, o pretor peregrino devia delimitar a controvérsia e encaminhá-la a um ou a vários árbitros (1980, p. 30).
\end{abstract}

O pretor peregrino, com o tempo, passou a redigir previamente modelos, esquemas abstratos das possíveis controvérsias que lhe caberia conhecer, publicando-os, através de um edictum. Foram esses modelos, espécies de programas da atividade do iudex, que vieram a se tornar as fórmulas.

\title{
40 PROCESSO DA COGNITIO EXTRA ORDINEM
}

O fim da república começa a partir da chegada ao poder de Otávio Augusto. Assumindo o título de Caesar e concentrando em si todo o poder antes repartido entre o senado, os cônsules, os tribunos e demais magistrados (inclusive a iuris dictio), Otávio inaugura a fase que ficou conhecida como o principado, fase imperial do Estado Romano, cujos limites territoriais chegam a abranger quase toda a Europa, o norte da África e uma parte ocidental da Ásia. Nesse momento, as instituições políticas romanas são redefinidas.

${ }^{3}$ Livre tradução nossa do original transcrito pelo romanista citado: "Q uod Aulus Augerius N umerio N egidio hominem vendidit, qua de re agitur, quidquid ob eam rem N umerium N egidium Aulo Augerio dare facere oportere ex fide bona, eius iudex Numerium N egidium Aulo Augerio condemnato; si non paret, absolvito." 
No que concerne à jurisdição, extingue-se dualidade de fases (in iure e apud iudicem), que, como visto, fazia com que o processo se desenrolasse primeiramente ante o pretor, para a fixação dos termos da controvérsia na fórmula, e, posteriormente, diante do árbitro, para a sua solução. O processo assume, em definitivo, feições públicas. Abandonam-se os excessos formalistas. Os órgãos julgadores, por delegação imperial, multiplicam-se, especializam-se e são distribuídos em instâncias, difundindo-se de modo a atingir toda a vasta extensão do império (TUCGI e AZEVEDO, 2001a, p. 141) . Passa-se a admitir a possibilidade de recurso contra a decisão dos magistrados, notadamente a appellatio (apelação) dirigida ao próprio imperador (TABOSA, 2006, p. 15) ${ }^{6}$.

\section{PROCESSO CIVIL NAEUROPA APÓSAQUEDADE ROMA}

No século quinto depois de Cristo, após uma longa trajetória de declínio moral, político, econômico e militar, Roma cai diante das hordas de povos bárbaros, que já há algum tempo repetidamente a assediavam. O mundo ocidental unificado desaparece e, em seu lugar, instaura-se uma desordem generalizada, com o surgimento e rápido desaparecimento de reinos bárbaros diversos, logo sucedidos por outros similares, destinados, igualmente, a uma existência atribulada e efêmera.

O contato entre essas duas civilizações - a vencedora, primitiva e bárbara, e a vencida, culta e civilizada - não foi fácil. No que diz respeito ao contato jurídico, eram ainda maiores, provavelmente, as discrepâncias, pois o direito romano atingira um alto grau de sofisticação e desenvolvimento, a que não podiam aspirar, então, os ordenamentos jurídicos dos povos invasores, a maioria ainda em pronunciado estágio de primitivismo, associado a manifestações religiosas e de magia, assim como alheio a qualquer sistematização.

Ainda assim, aquilo que hoje se conhece como família jurídica romano-germânica é o legítimo fruto desse contato entre as duas díspares culturas: contato inicialmente difícil, mas enriquecedor, ao final de contas (DAVID, 1998, p. 25).

\footnotetext{
5 Os autores, ainda, discriminam, entre outros, os seguintes magistrados judicantes: praetor urbanus, praetor tutelarius, praetor de liberalibus causa, praefectus urbi, praefectus praetorio, procuratores fisci, cada um dos quais com atribuições para o julgamento de certas e específicas causas, de suas decisões cabendo recurso a órgãos superiores.

${ }^{6}$ O professor cearense se refere ao episódio descrito no texto bíblico, mais precisamente no livro dos Atos dos Apóstolos, 25, 11, em que o apóstolo São Paulo, acusado injustamente de crimes contra os judeus, nega tal prática e, invocando sua condição de cidadão romano, afirma: "Mas se de fato cometi uma injustiça ou pratiquei algo que mereça a morte, não recuso morrer. Se, ao contrário, não há nada daquilo de que me acusam, ninguém pode entregar-me a eles. Apelo para César!”
} 


\section{PROCESSO NO DIREITO JUSTINI ANEU}

Em Constantinopla, após a queda de Roma, sobrevive o direito romano, regendo a parte oriental do império, que se manteve incólume às investidas bárbaras. Aí reinará Justiniano, celebre imperador, cujas muitas conquistas militares, entretanto, acham-se completamente obscurecidas, com razão, pela relevância de sua contribuição à cultura jurídica universal.

A grande compilação de normas, conhecida como C orpus I uris Civilis, é realizada sob sua ordem e inspiração, sendo concluída em 529, depois de Cristo. Trata-se, como dito, de uma compilação (mas não de um código, no sentido moderno da palavra), em que estão reunidos textos de diferentes épocas do direito romano, em quatro diferentes partes: o código (codex vetus) é fundamentalmente uma coletânea de antigas leis, ainda vigentes à época da elaboração da compilação; o digesto ou pandectas (digestum, pandectae) é uma espécie de enciclopédia jurídica; as institutas (institutiones) são um manual para estudantes, e as novelas (novellae constitutiones) são um conjunto de determinações imperiais, com força de lei (Alves, 2000, vol. I, p. 46-47).

Nessa grande obra, a matéria processual, dispersa ao longo de suas diversas partes, reflete basicamente o direito romano do fim do império, não havendo qualquer inovação substancial, senão uma adaptação às circunstâncias e à época ${ }^{7}$.

Merece um destaque especial o fato de que a compilação se baseia, sobretudo, nos escritos de cinco dos mais famosos jurisconsultos romanos, a saber: Paulo, Papiniano, Ulpiano, Modestino e Gaio, cujos nomes ficaram celebrizados como componentes daquilo que, curiosamente, ficou conhecido como o tribunal dos mortos (ALVES, 2000, p. 44) ${ }^{8}$.

\section{O PROCESSO NO DIREITO DOS POVOS GERMÂNICOS E NO DIREITO FEUDAL}

Sob o nome genérico de germanos, relaciona-se, em verdade, um grande grupo de tribos diversas, "falando múltiplos dialetos, obedecendo a um chefe e ligando-se entre si por antigas tradições e laços de parentesco ou, ainda, com base na consanguinidade ou na crença de um antepassado comum [....]" (SURGIK, 2004, p. 45). O direito vigente

\footnotetext{
Moreira Alves, todavia, lembra (2000, vol. I, p. 51-53) que o direito romano, no dominato, sofreu influência do cristianismo.

${ }^{8}$ Os cinco juristas mencionados viveram na época clássica do direito romano, mas, apesar de há muito mortos, suas opiniões em temas jurídicos, por determinação dos imperadores Teodósio II e Valentiniano III (aproximadamente na metade do século $\mathrm{V}$ depois de Cristo), foram tornadas as únicas admissíveis nos tribunais. Havendo divergência, prevalecia a opinião majoritária e, em caso de empate, a opinião de Papiniano.
} 
entre tais povos, à época da queda de Roma, era ainda bastante primitivo, em geral baseando-se em tradições antigas e costumes há muito consolidados, transmitidos de geração em geração principalmente por via oral (CAENEGEN, 2000, p. 26).

Do contato entre as duas civilizações, resulta um direito híbrido, que mescla características de cada povo. Não chega a desaparecer o direito romano, mas sua incidência fica restrita às populações latinas, ao passo que os germanos continuavam submetidos à sua própria ordem jurídica. Posteriormente, o direito feudal - de natureza fundamentalmente consuetudinária - tomará corpo e, durante cerca de quatro séculos, se manterá vigente em solo europeu ${ }^{9}$.

O mundo medieval é um mundo em que inexiste a unidade do Estado, que deu lugar a incontáveis feudos, cada qual com sua jurisdição local. Já não há juízes profissionais, mas “juízes ocasionais, sem qualquer formação específica” (CAENEGEN, 2000, p. 35-36).

O processo, nesse contexto, também se modifica profundamente, não mais guardando semelhança com o antigo processo romano, da cognição extraordinária. Os julgamentos ocorriam ao ar livre, em praça pública, de forma oral e com a presença do povo, cuja participação era ampla. Inexistiam registros escritos e a causa normalmente se resumia a uma disputa entre as partes, ou entre as testemunhas de ambas, chegando, às vezes, inclusive ao duelo ou a supostas manifestações divinas. Os juízes não exerciam qualquer valoração crítica da prova, mas limitavam-se a referendar o resultado da disputa (KEMMERICH, 2006, p. 51-67).

\section{PROCESSO CANÔNICO}

Paralelamente, como único poder centralizado da era medieval, a Igreja Católica Romana elabora seu próprio ordenamento jurídico, que passa a ser conhecido como direito canônico ${ }^{10}$. A origem do processo canônico parece estar relacionada a uma interessante determinação de São Paulo, ainda nos primórdios do cristianismo.

\footnotetext{
${ }^{9}$ A natureza basicamente consuetudinária do direito feudal, inegável que seja, não elide fato de que alguns esboços de legislação medieval merecem destaque: assim as capitulares, leis do reino franco ao tempo de Carlos Magno, bem como a legislação dos visigodos em Portugal, conhecida como lex romana visigothorum.

${ }^{10} \mathrm{O}$ adjetivo canônico deriva da palavra cânon, de origem grega, significando regra, ou disciplina (SILVA, 2006, p. 248). Nas grandes codificações eclesiásticas, as normas jurídicas acham-se dispostas em cânones, numerados como os artigos das leis estatais. À guisa de ilustração, veja-se o teor do cânon - de natureza processual - no 1.419: "Cân. $1.419-\S 1^{\circ}$. Em cada diocese e para todas as causas não expressamente excetuadas pelo direito, o juiz de $1^{a}$ instância é o Bispo diocesano, que poderá exercer o poder judiciário pessoalmente ou por outros, segundo os cânones seguintes. $\S 2^{\circ}$. Tratando-se, porém, de direitos ou de bens temporais de uma pessoa jurídica representada pelo Bispo, julga em primeiro grau o tribunal de apelação."
} 
De fato, sabe-se que os primeiros cristãos, vivendo em catacumbas, não apenas tinham suas controvérsias espirituais, como também, às vezes, viam-se às voltas com querelas relativas a bens materiais, que eram julgadas pelos tribunais romanos. Não convindo, contudo, à nascente religião cristã - perseguida pelos imperadores - que essas controvérsias internas fossem julgadas por pagãos, interveio o Apóstolo dos Gentios:

\begin{abstract}
Determinou São Paulo que os conflitos entre cristãos deveriam ser dirimidos, a princípio, pelo chefe do grupo integrado pelos litigantes, ou por um bispo, ou até pelo Papa, mas sempre por um dirigente da Igreja. A estratégia de São Paulo objetivava evitar que os pagãos argumentassem que mesmo no seio dos próprios cristãos havia discórdia. Preconizava o Apóstolo: 'Há entre vós quem, tendo um questão com outro, ouse sujeitar-se a julgamento perante os injustos (pagãos) e não perante os santos? Será que não existe entre os cristãos um único homem capaz de julgar litígio entre irmãos? ' (Paulo, Cor., 6.1.). Assim, pregando São Paulo estava criando um outro tipo de jurisdição paralelo à justiça romana, à justiça laica (TUCAI e AZEVEDO, 2001b, p. 17-18).
\end{abstract}

O processo canônico exerceu forte influência sobre os direitos locais, em toda a idade média, a ponto de vários institutos de origem eclesiástica virem a ser adotados, mais tarde, pela jurisdição estatal (como, por exemplo, o procedimento sumário, para causas mais simples) (TUCGI e AZEVEDO, 2001b, p. 57) ${ }^{11}$.

\title{
9 ARECEPÇÃO DO DIREITO ROMANO
}

O fenômeno conhecido como recepção do direito romano, durante a baixa Idade Média, tem natureza complexa. O estudo do Corpus I uris Civilis, realizado de forma sistemática, aproximadamente a partir do ano 1100 da era cristã, renovou o interesse pelo direito romano, dando origem a um movimento cultural de retorno à pesquisa de suas fontes, recuperação de documentos e a uma investigação aprofundada.

Inicialmente na Itália, em Bolonha sobretudo, mas depois passando a toda a Europa continental, iniciam-se pesquisas, que terminam por fazer prevalecer um direito mais ou menos comum a todo o continente (direito que ficou conhecido como ius commune), com grande vantagem sobre os incontáveis sistemas feudais porque se tratava de um direito escrito, comum em todos os lugares, mais completo, mais racional, com prevalência da lei sobre os múltiplos e confusos costumes locais (GILISSEN, 2001, p. 202-205).

${ }^{11}$ Referem os autores que o procedimento sumário tem origem em um célebre decreto papal, datado de 1306, conhecido como Clementina Saepe. 
O desenvolvimento do estudo jurídico é notável, florescendo diversas escolas, entre as quais alinham-se os glosadores ${ }^{12}$, pós-glosadores e a escola culta, com nomes que ficaram conhecidos nos anais da história do direito, entre os quais avultam os de Acúrcio, Bártolo, Cujácio e Durand, autor de célebre obra processual, denominada Speculum Iudiciale (ORESTANO, 1999, p. 192) ${ }^{13}$.

Os estudos romanísticos continuaram ao longo dos séculos, sobretudo na Europa continental, de onde se espalhou a influência do processo romano para as colônias de além-mar que Espanha, Portugal, França, Holanda e Inglaterra estabeleceram a partir do fim do século XV.

\section{CONCLUSÃO: A SOBREVIVÊNCIADO PROCESSO ROMANO NAERACONTEMPORÂNEA}

O processo no mundo contemporâneo precisa estar apto a atender a outras exigências, em larga medida alheias ao espírito que norteou a formação e, ao longo dos milênios, o desenvolvimento do processo romano.

Acentuam-se a natureza e a função instrumentais do processo e, assim, cobra-se celeridade na resolução dos litígios, em cujo nome sumariza-se a cognição e antecipa-se a tutela; aventam-se formas novas e mais expeditas de execução sincrética, em que os procedimentos são simplificados e dotados de meios mais eficazes (como a penhora de saldos bancários on-line); abandona-se o excesso de formalismo e busca-se a concentração dos atos processuais, favorecendo-se a oralidade, em detrimento das velhas fórmulas forenses; atendidos os parâmetros legais - plena capacidade dos interessados, disponibilidade e patrimonialidade dos direitos envolvidos, entre outros - estimula-se a solução arbitral dos conflitos.

Tudo isso, se por um lado aparenta ter um forte sabor moderno, é certo que, de outra parte, não nasce do nada, assim simplesmente ex nihilo, como se a mente fértil dos processualistas e legisladores contemporâneos lograsse descobrir e inventar o que antes a ninguém ocorrera. Ao contrário, quando investigada com mais atenção, cada inovação processual termina por evidenciar, em alguma medida, sua raiz romana, atestando a sobrevivência e a perenidade do gênio jurídico do grande povo latino.

\footnotetext{
${ }^{12}$ R A denominação glosadores decorre do método de estudo empregado por aqueles estudiosos: costumavam fazer pequenos comentários, ou glosas, entre as linhas ou à margem do texto do Corpus Iuris Civilis. Confira-se mais em Alves (2000, vol I, p. 58).

${ }^{13} \mathrm{O}$ autor (1999, p. 186) acentua - a respeito do imenso prestígio de que gozava a compilação de Justiniano que chegou-se a considerá-la um presente de Deus (donnum Dei), ao mesmo tempo em que o conhecimento do direito nela contido veio a ser reputado como o verdadeiro conhecimento legal (sapientia legalis).
} 


\section{REFERÊNCIAS}

ALVES, José Carlos Moreira. Direito romano. Rio de Janeiro: Forense, 2000.

ARANGIO-RUIZ, Vincenzo. Cours de droit romain - les actions. Napoli: Jovene, 1980.

CAENEGEN, R. C. van. Uma introdução histórica ao direito privado. São Paulo: Martins Fontes, 2000.

DAVID, René. Os grandes sistemas do direito contemporâneo. São Paulo: Martins Fontes, 1998.

DE PLÁCIDO E SILVA. Vocabulário jurídico. Rio de Janeiro: Forense, 2006.

GAIUS. Institutas. São Paulo: Revista dos Tribunais, 2004.

GILISSEN, John. Introdução histórica ao direito. Lisboa: Calouste Gulbenkian, 2001.

IHERING, Rudolf von. L'Esprit du droit romain. Bolonha: Arnaldo Forni, 2004.

KASER, Max. Direito privado romano. Lisboa: Calouste Gulbenkian, 1999.

KEMMERICH, Clóvis Juarez. O direito processual da idade média. Porto Alegre: Sérgio Antônio Fabris, 2006.

MEIRA, Ś́lvio. Processo civil romano. Belém: Falangola, s/d.

ORESTANO, Riccardo. Introduzione allo studio del diritto romano. Bologna: Il Mulino, 1999.

SURGIK, Aloísio. Gens gothorum: as raízes bárbaras do legalismo dogmático. Cultura: Livro é Cultura, 2004.

TABOSA PINTO, Agerson. Civis romanus sum - teoria e prática da cidadania: o caso de São Paulo. Fortaleza: Faculdade 7 de Setembro, 2006.

TUCAI, José Rogério Cruz e; AZEVEDO, Luiz Carlos de. Lições de história do processo civil romano. São Paulo: Revista dos Tribunais, 2001a.

Lições de processo civil canônico - história e direito vigente. São Paulo: Revista dos Tribunais, 2001b.

WINDSCHEID, Bernhard. L'Actio del diritto civile romano dal punto di vista del diritto odierno. In Polemica intorno all'actio di W indscheid-M utter. Firenza: Sansoni, 1999. 
TIMELESSINFLUENCE OF ROMAN CIVIL PROCEDURE ON CONTEMPORARY PROCEDURAL INSTITUTIONS

Abstract: The influence of Roman Law on all western juridical systems is widely known. Likewise, this influence on the procedural field is easily recognized. This article aims to analyze the various phases of the Roman process and its evolution during the rise of the Roman empire and even after centuries that followed its decline. It also seeks to detect the most visible traits of this influence on the modern procedural institutes. The relationship between Roman Law and the new barbarian cultures as well as with the canonical legal procedure is examined here, to conclude, after all, for the survival of Roman Law and for the need of its study in Law schools.

Keywords: Roman Law. Civil Procedure. 